\title{
Development of Methodology for the Isolation and Determination of Propafenone in Blood Samples via HPLC
}

\author{
Madina Alikhodjaeva ${ }^{1}$, Alisher Atahanov ${ }^{1}$ and Mirzabotir Xamdamov ${ }^{2}$ \\ 1. Department of Toxicological, Organic and Biological Chemistry, Tashkent Pharmaceutical Institute, Tashkent 100015, Uzbekistan \\ 2. Scientific Centre of Medicine Standardization, Tashkent Pharmaceutical Institute, Tashkent 100015, Uzbekistan
}

\begin{abstract}
In clinical practice, side effects of anti-arrhythmic medicines such as propafenone are commonly registered. Therapeutic drug monitoring is a solution to the problem regarding to side effects of drugs and aiming to control substance concentration in biological fluids. The objective of the research is the development of a methodology for isolation and determination of propafenone in whole blood. Liquid-liquid extraction method was used for the isolation propafenone, which was done at $\mathrm{pH} 4$, via acetate buffer and with chloroform used as an extraction agent. HPLC (high performance liquid chromatography), TLC (thin layer chromatography) and UV (ultra violet) spectrophotometric methodology for identification and quantitative determination of propafenone was established. The developed method of isolation and determination of the propafenone was tested by studying the blood of volunteers who received therapeutic concentrations $(150 \mathrm{mg})$ of these drugs in the form of tablets. TLC methodology allows to determine and to purify an extract. Chromatographic system including chloroform, ethyl acetate and ethanol (10:3:1) were determined at Rf 0.42 for propafenone. UV-spectroscopy analysis illustrated maximum absorption at 248 and $304 \mathrm{~nm}$. HPLC is considered as the most precise and accurate method allowing qualitatively and quantitatively determine propafenone in therapeutic concentrations of blood $(0.46-0.88 \mu \mathrm{g} / \mathrm{L}$ in a single dose $150 \mathrm{mg}$ ).
\end{abstract}

Key words: Propafenone, extraction, TLC, HPLC, UV spectroscopy, blood.

\section{Introduction}

Cardiovascular diseases are the regional pathology in Uzbekistan. Antiarrhythmic drugs are commonly used to treat VA (ventricular arrhythmias). Ventricular arrhythmias include a large group of heart rhythm disturbances, uniting on the basis of the source of pathological impulses [1]. Potentially dangerous VA, whose adverse prognostic significance is confirmed in large prospective studies as well as malignant VA, carry a direct threat to the development of fatal arrhythmias [2]. The best choice would be the drugs from class IC [3]. Propafenone is a well-established IC class anti-arrhythmic drug widely used in the treatment of supraventricular and ventricular tachyarrhythmas.

Corresponding author: Madina Alikhodjaeva, Ph.D., associate professor, research field: pharmacy and toxicological chemistry.
The need for a combination of anti-arrhythmic drugs arises with disordered appearance of resistant forms of arrhythmias. The purpose of this assignment is to reduce the frequency ventricular ectopic activity to eliminate painful symptoms. Additionally, the risk of any adverse side-effects is unacceptable [4]. Side effects of antiarrhythmic drugs are commonly appearing in clinical practice of cardiology. Anti-arrhythmic medicines can have negative effect on heart's normal rhythm, leading to creation of blocks and arrhythmia.

There are a number of lethal intoxications reported in various literatures indicating to fatal propafenone overdoses [5]. Their usage is associated with discomfort and often limited due to their toxicity. Since pharmacological effects (such as the suppression of arrhythmias and toxicity) linked with the concentration 
of drug in plasma, the treatment should be organized so as to maintain the concentration above the minimum required to eliminate the arrhythmia and lower than concentrations causing side effects.

Therapeutic drug monitoring is a solution to the problem regarding side effects of drugs and aiming to control substance concentration in biological fluids. Therefore, there is a need for development of an analytical methodology for the identification and quantification of propafenone in biological fluids.

Propafenone is chemically 1-(2-[2-Hydroxy-3-(propylamino)-propoxy]-3-phenyl propan-1-one hydrochloride (Fig. 1). It occurs as colorless crystals or white crystalline powder with a very bitter taste. It is slightly soluble in water $\left(20^{\circ} \mathrm{C}\right)$, chloroform and ethanol.

Propafenone is administered orally in doses of 150 mg every 8 hours, with some patients receiving as much as $300 \mathrm{mg}$ every 8 hours. Following oral doses of either $300 \mathrm{mg}$ of propafenone to 8 healthy volunteers, peak serum concentrations of the drug ranged from 37-256 $\mu \mathrm{g} / \mathrm{L}$ [6]. Patients have survived the acute ingestion of $1800-9000 \mathrm{mg}$ of the drug after attaining plasma propafenone concentrations of $1100-4700 \mu \mathrm{g} / \mathrm{L}$ $[7,8]$. A man found dead after an apparent propafenone overdose had postmortem blood and liver levels of 9.1 $\mathrm{mg} / \mathrm{L}$ and $230 \mathrm{mg} / \mathrm{kg}$, respectively [9].

There are various analytical methods used for determination of propafenone. They are UV spectrophotometry, HPLC (high performance liquid chromatography) method, HPTLC (high performance thin layer chromatography) method and UFLC (Ultra-fast liquid chromatography), which are considered as time efficient analytical tools for estimation of propafenone hydrochloride in pharmaceutical dosage form [10-13]. Some methods report the estimation of substance in biological samples particularly from plasma [14-15]. In this study, we made an attempt to develop a simple, precise and cost effective method for determination of propafenone in biological fluids.

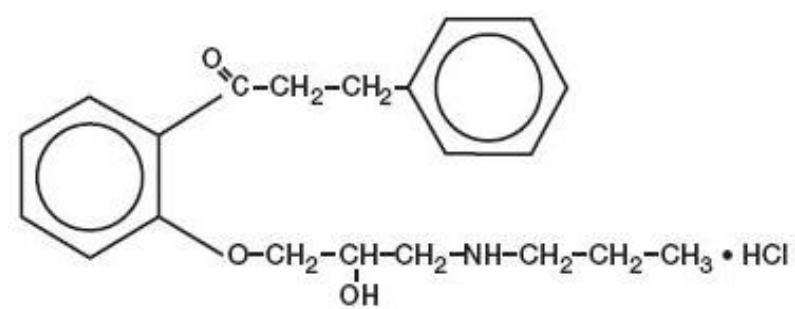

Fig. 1 Chemical structure of Propafenone hydrochloride.

\section{Materials and Methods}

\subsection{Analytical Instrumentation and Chemicals}

HPLC “Agilent 1100 series" (Agilent Technologies, USA); UV spectrophotometer "Agilent 8453 UV/VIS" (Agilent Technologies, USA); UV-lamp GAMAG (Germany); 20 TLC aluminium sheets, $20 \times 20 \mathrm{~cm}$, RP-18-F 254 (MERCK KGa A, Germany); Propafenone $\mathrm{HCl}$ (standard) 6216, Lot No:1489, (99.7\%) PharmaZell GmbH (Germany); Acetonitrile for preparative HPLC (Germany); Chloroform for liquid chromatography (Merck, Germany); Ammonium acetate, A, R HIMEDIA (Mumbai); Acetic acid $\geq$ 99.8\%, SIGMA-ALDRICH Germany; Ethyl acetate “ЭКОС-1, ч.д.а." (Russia); Ethanol "DORI-DARMON" (Uzbekistan).

\subsection{Instrumental and Analytical Conditions}

For this purpose, the blood of volunteers was used as objects. Firstly, experiments were carried out on the model samples, and then developed method of analysis was implemented in the study of blood obtained from the veins of volunteers who received propafenone orally in doses of $150 \mathrm{mg}$.

To $3 \mathrm{ml}$ of blood obtained from a vein, $1 \mathrm{ml}$ of buffer solution ( $\mathrm{pH}$ 4.0) was added and centrifuged. The supernatant was separated and $1 \mathrm{ml}$ of a buffer solution (pH 4.0), $1 \mathrm{ml}$ saturated solution of sodium chloride were added and stirred to the supernatant. From this mixture, propafenone was extracted with chloroform (3 $\mathrm{ml}$ ) three times. The chloroform extract were combined and evaporated on a steam bath until appearance of dry residue. Dry residue was analyzed by the methods of TLC, UV spectrophotometry and HPLC. 


\section{Propafenone in Blood Samples via HPLC}

\subsubsection{TLC}

The residue was dissolved in $0.5-1.0 \mathrm{ml}$ of ethanol, which is applied to the chromatographic plate. It was conducted by the method of TLC via MERCK chromatographic plate (20 TLC aluminium sheets, $20 \times$ $20 \mathrm{~cm}, \mathrm{RP}-18-\mathrm{F}_{254}$ ) and a mixture of chloroform was used as a solvent system, ethyl acetate and ethanol in 10:3:1 ratio as mobile phase. UV irradiation was used at $254 \mathrm{~nm}$ for visualization of the spots on the plate. The chloroformed extracts were purified by TLC method. As a result, propafenone has Rf $0.42 \pm 0.01$, and ballast substances are on the start line and at the front.

\subsubsection{UV Spectrophotometry}

Zone of substance accumulation was eluted with ethanol and extracts was investigated by the methods of UV spectroscopy.

Spectrophotometric analysis was performed with a spectrophotometer of the company (Agilent Technologies). To identify propafenone, ethanol solution of the standard sample with concentration of $24 \mu \mathrm{g} / \mathrm{ml}$ was utilized. When measuring the absorbance of a standard solution of propafenone, two absorption peaks at a wavelength of $248 \mathrm{~nm}$ and $304 \mathrm{~nm}$ in the range of 200-400 nm were observed. UV absorption spectrum of ethanol solution of propafenone is shown in Fig. 2.

In order to conduct quantitative determination of propafenone via UV spectrophotometry, the following procedure is used: For quantitative determination of propafenone, ethanol solution containing 12.0; 24.0; $36.0 ; 48.0 ; 60.0 \mu \mathrm{g} / \mathrm{ml}$ propafenone were prepared. The absorbance of each solution in the UV spectrophotometer was measured. As a comparative solution, the ethanol solution was used. The gained results can be used to calculate the specific and molar absorption coefficient, which are shown in Table 1 and Fig. 3.

The data presented in Table 1 shows that linearity was observed in concentration range of $5.0-60.0 \mu \mathrm{g} / \mathrm{ml}$.

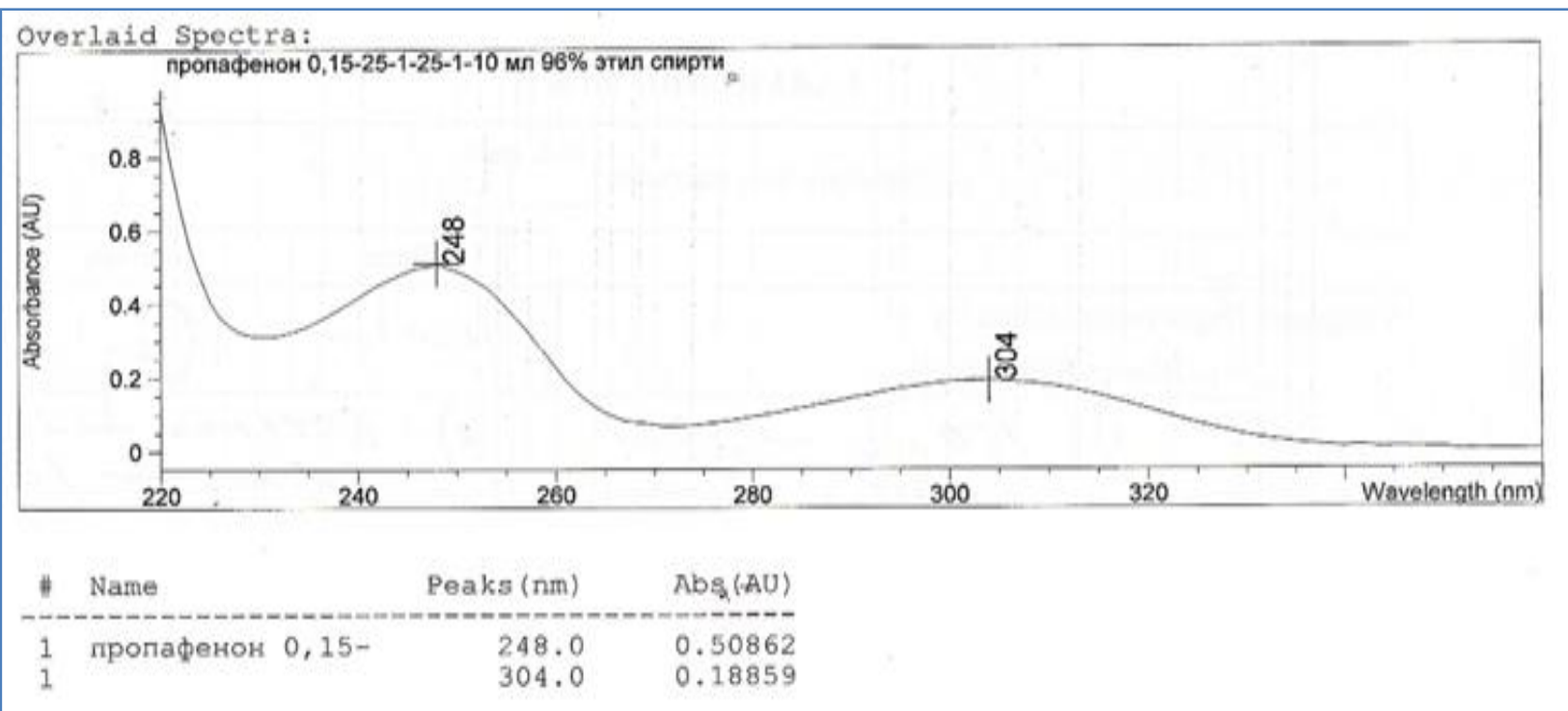

Fig. 2 UV-spectrum of propafenone's standard solution in ethanol propafenone.

Table 1 Results of determination of specific and molar absorption coefficients of propafenone in ethanol.

\begin{tabular}{llll}
\hline Concentration $\mu \mathrm{g} / \mathrm{ml}$ & $\mathrm{D}$ & $\mathrm{E}$ & $\mathbf{E}$ \\
\hline 12 & 0.25220 & 210.1 & 7939.6 \\
24 & 0.50904 & 212.1 & 8015.2 \\
36 & 0.76320 & 212.0 & 8011.4 \\
48 & 1.01472 & 211.4 & 7988.8 \\
60 & 1.27140 & 211.9 & 8007.7 \\
\hline
\end{tabular}


In addition to the calibration curve for the quantitative determination of propafenone the following formula can be deployed:

$$
X=\frac{D \cdot V_{1} \cdot 1000}{E_{1 c m}^{1 \%} \cdot 100 \cdot V_{2}}
$$

where, D-absorbance of the solution;

$E_{1 s m}^{1 \%}$ - Specific absorption rate of propaferone. ;

$\mathrm{V}_{1}$ - volume of the researched solution, in $\mathrm{ml}$;

$\mathrm{V}_{2}$ - volume of isolation, in $\mathrm{ml}$.

\subsubsection{HPLC}

HPLC analysis was conducted by using Agilent Technologies 1100 series equipment with UV detection at $242 \mathrm{~nm}$ and Spherisorb SCN column $(4.6 \times$ $120 \mathrm{~mm}, 3 \mu \mathrm{m})$. The mobile phase was a mixture of acetonitrile and buffer (in 50:50 ratio) and delivered at a flow rate of $0.7 \mathrm{ml} / \mathrm{min}$.

\subsubsection{Preparation of Mobile Phase}

Buffer: 7.7 gram ammonium acetate dissolved in
$900 \mathrm{ml}$ water then it is acidified with acetate acid till pH 6.0 after that it was diluted till $1000 \mathrm{ml}$ (pH 6.0).

Afterwards, $500 \mathrm{ml}$ acetonitrile was added to $500 \mathrm{ml}$ buffer solution and obtained mixture was degassed in ultrasonic water bath for 5 minutes.

\subsubsection{Standard Solution Preparation}

Standard stock solution of propafenone was prepared by dissolving $12 \mathrm{mg}$ of the drug in $10 \mathrm{ml}$ of mobile phase and was ultra-sonicated for 5 min. Finally, the volume was made up to $50 \mathrm{ml}$ with mobile phase, which gave $24 \mu \mathrm{g} / \mathrm{ml}$ solution.

From the standard stock solution, the various dilutions of propafenone in the concentration of 30.5 ; $61 ; 122 \mu \mathrm{g} / \mathrm{ml}$ were prepared; each of these solutions $(20 \mu 1)$ was injected three times in to the HPLC system under cromatografic condition and the peak areas and retention times were recorded. The results are shown in Fig. 4 and Table 2.

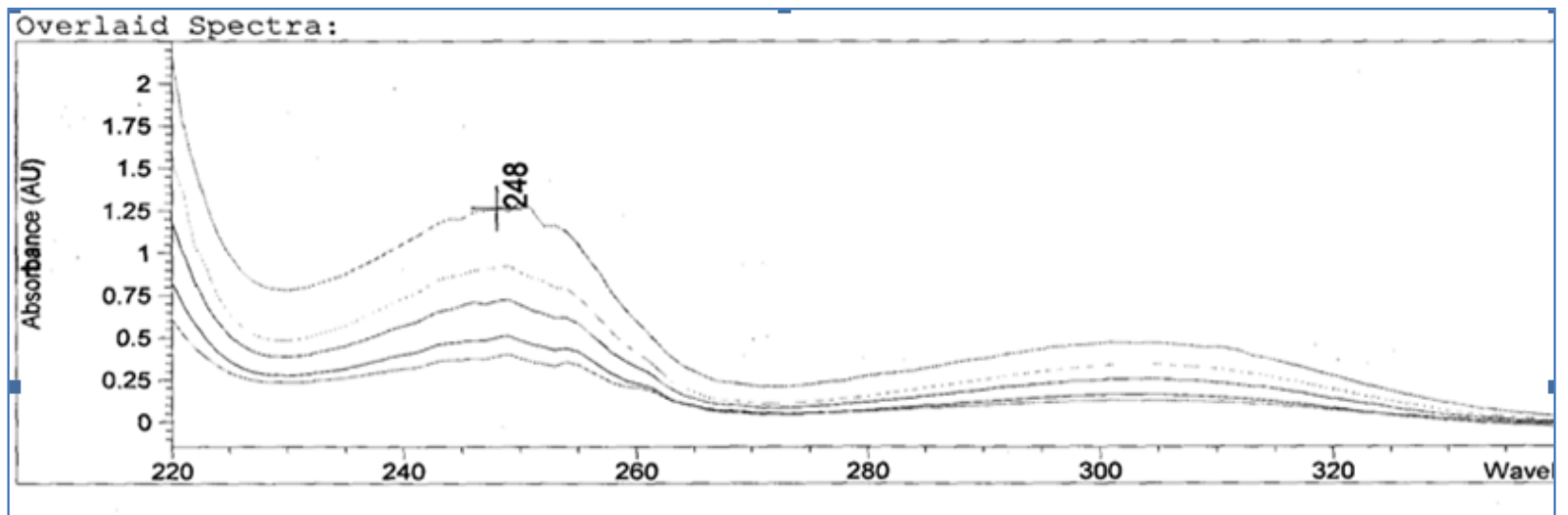

Fig. 3 UV-spectrum of propafenone's various solutions.

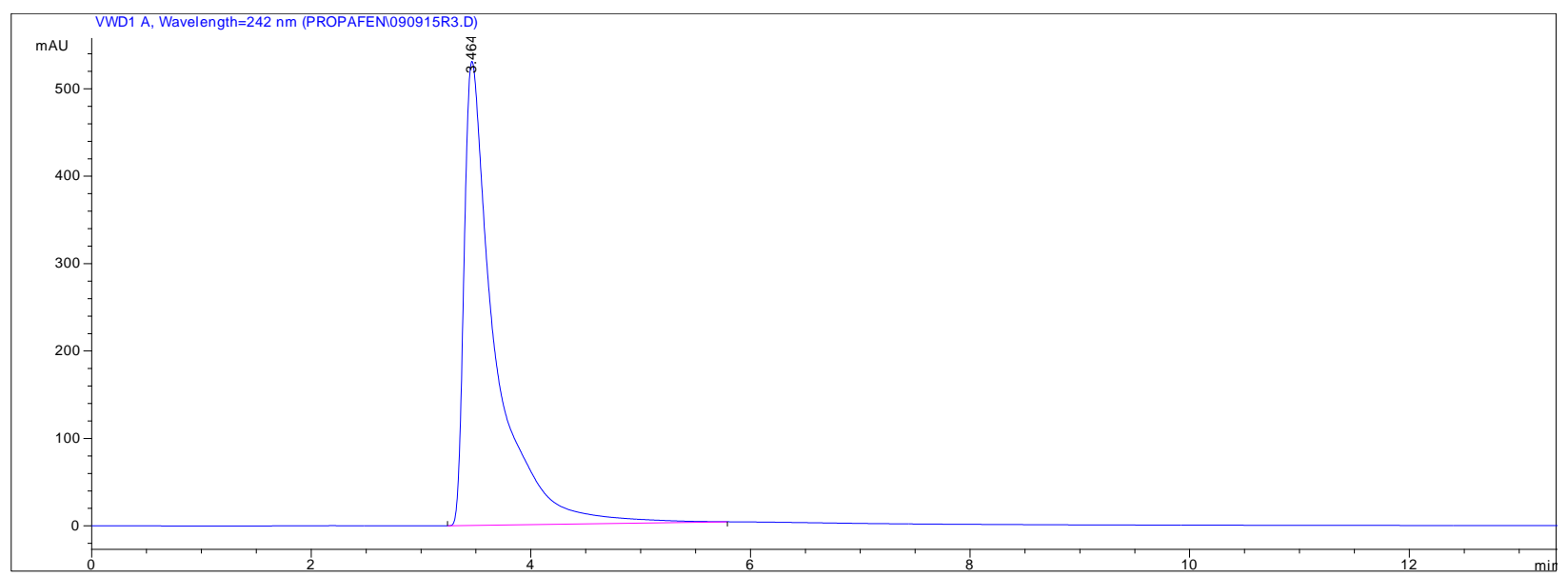

(a) standard sample chromatogram of propafenone (RSO propafenone $0.244 \mathrm{mg} / \mathrm{ml}$ ) via HPLC 
Development of Methodology for the Isolation and Determination of

167 Propafenone in Blood Samples via HPLC

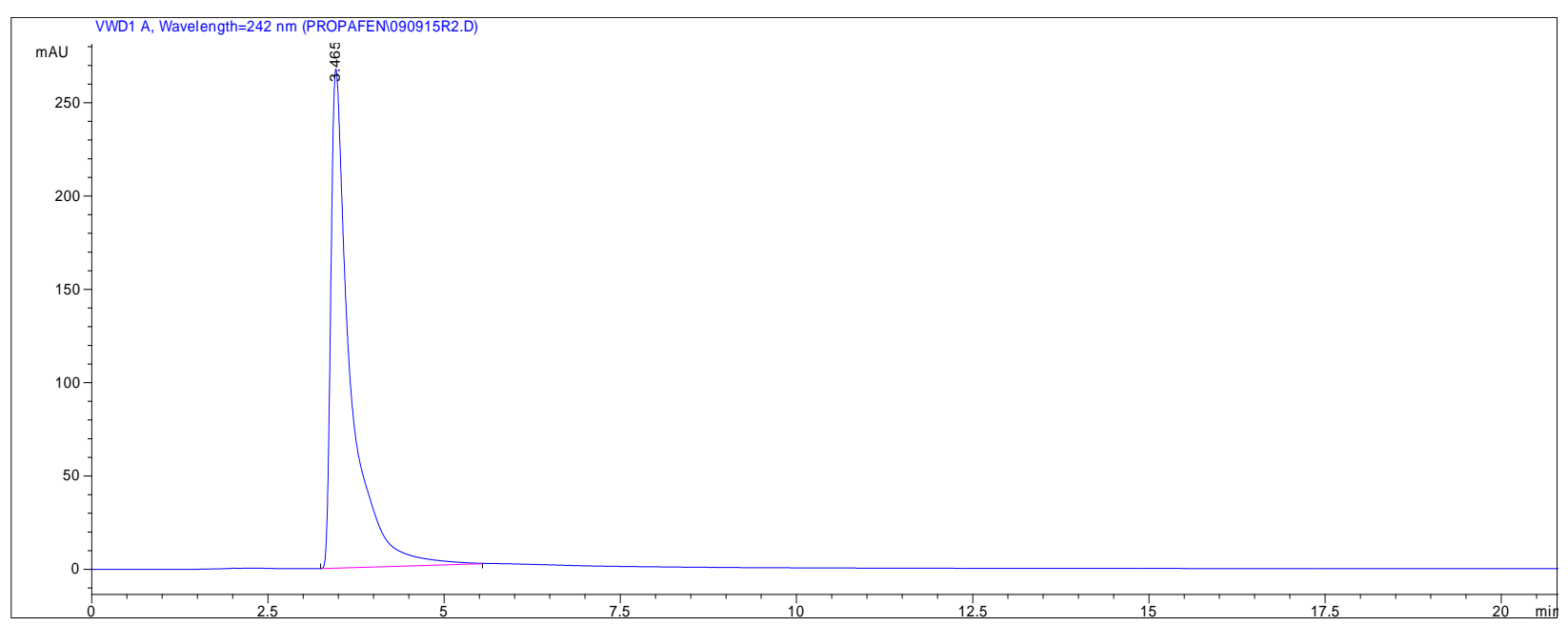

(b) Standard sample chromatogram of propafenone (RSO propafenone $0.122 \mathrm{mg} / \mathrm{ml}$ ) via HPLC

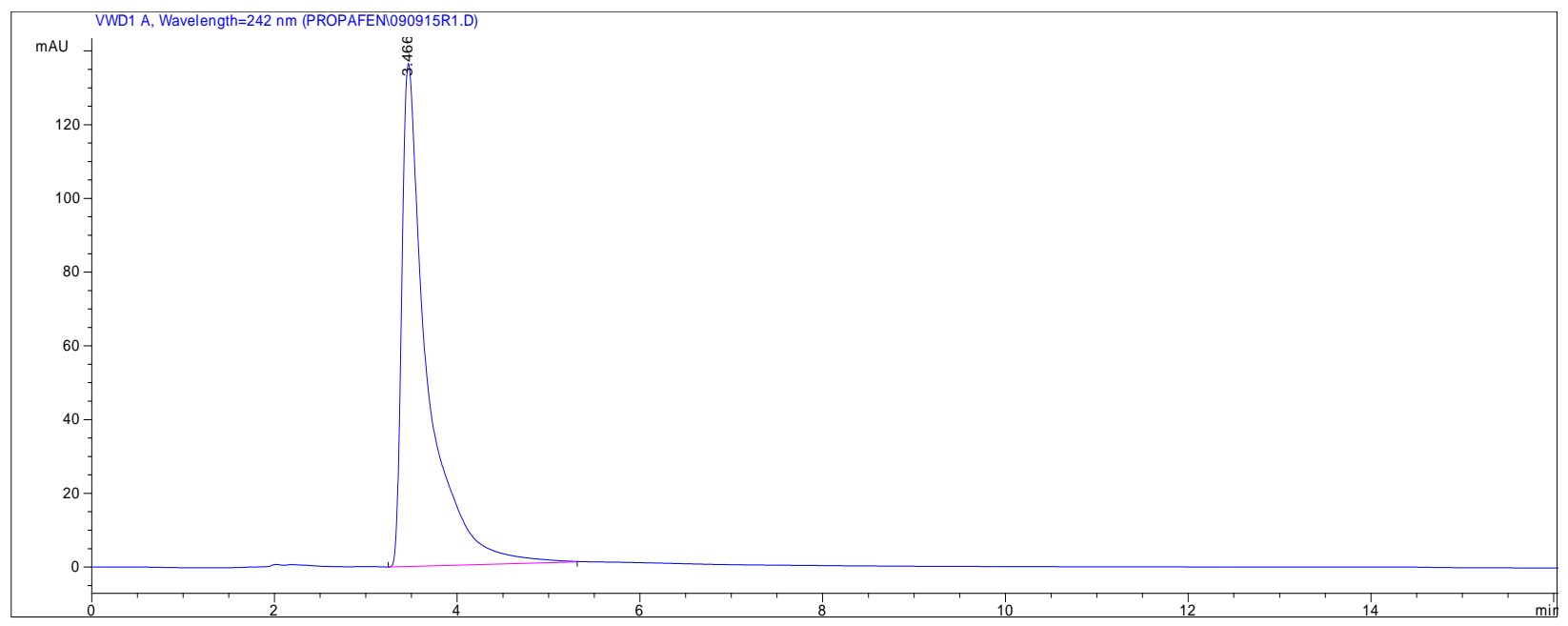

(c) Standard sample chromatogram of propafenone (RSO propafenone $0.06 \mathrm{mg} / \mathrm{ml}$ ) via HPLC

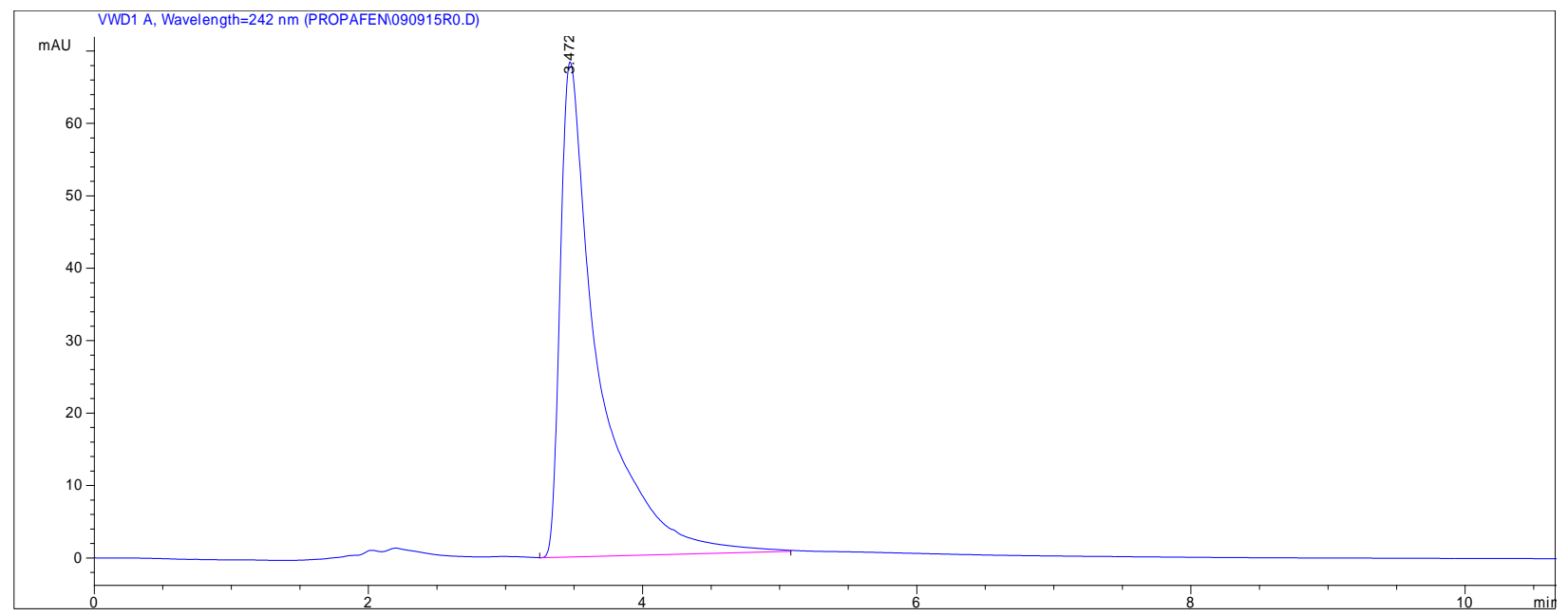

(d) Standard sample chromatogram of propafenone ( $\mathrm{RSO}$ propafenone $0.0305 \mathrm{mg} / \mathrm{ml}$ ) via HPLC

Fig. 4 Chromatograms of standard samples of propafenone. 
Table 2 Results of quantitative analysis of propafenone via HPLC methodology.

\begin{tabular}{llll}
\hline Concentration, $\mathrm{mg} / \mathrm{ml}$ & $\mathrm{H}$ & Peak area S & Retention time (min) \\
\hline 0.0305 & 68.375 & 1318.7677 & 3.472 \\
0.061 & 136.4263 & 2624.8154 & 3.466 \\
0.122 & 267.4818 & 5163.3999 & 3.465 \\
0.244 & 531.0797 & 10388.3 & 3.464 \\
\hline
\end{tabular}

\section{Results and Discussion}

TLC method is simple and convenient to analyze the propafenone in various biological objects and it can be used for semi-quantitative determination of substances in cases related to overdose with propafenone.

Identification of propafenone via methods of TLC and UV spectroscopy illustrated the following results in aforementioned conditions: Rf 0.42 , which allows to purify the substance from ballast as well as co-extractive substances and via elution spectrophotometric determination was carried out, as a result, two absorption maxima were recorded at 248 and $304 \mathrm{~nm}$ respectively in the UV spectrum.

Analysis of propafenone by HPLC methodology is described in a variety of sources: a number of studies devoted to the analysis of substances in medicines, in which objects are cleaner and the medical means are in pill with sufficient quantities $[16,17]$. The scientific work devoted to the investigation of poisoning cases with propafenone, was conducted by using the analysis of plasma. It also contains a large number of substances used in postmortem investigations.

The developed methodology of HPLC can be used in the therapeutic monitoring of propafenone and at the same time in these conditions, $1 \mathrm{C}$ class antiarrhythmic drugs such as amiodarone, VFS, atenolol and etatsizin can be defined [18].

Determination of propafenone by HPLC has been evaluated by looking at retention time of the standard solution of propafenone- $-3.47 \mathrm{~min}$.

The developed method of isolation and determination of the propafenone was tested by studying the blood of volunteers who received therapeutic concentrations of the drug in the form of tablets $(150 \mathrm{mg})$. After $1.5-2$ hours, $3 \mathrm{ml}(5 \mathrm{ml})$ of their blood was obtained from the vein and the sample preparation was performed under the aforementioned conditions.

In some studies, the usage of a buffer solution with $\mathrm{pH} 9.0$ to isolate propafenone from plasma was illustrated. In this investigation, a buffer solution with $\mathrm{pH} 4.0$ was used, by relying on the experience of experts in forensic toxicology (Kramarenko, V.F.), who stated that substances are better isolated from biological objects in acidified aqueous solutions. In addition, dependence of propafenone extraction from aqueous solutions on $\mathrm{pH}$ was verified. To do this, extraction of propafenone was done in the following conditions: to $9 \mathrm{ml}$ of buffer solution with $\mathrm{pH} 4.0$ (pH 9.0) $1 \mathrm{ml}$ of ethanol solution of propafenone was added and stirred, then extracted with $10 \mathrm{ml}$ of chloroform a single time. The chloroform extract was evaporated and the dry residue was dissolved in $3 \mathrm{~mL}$ of mobile phase which was chromatographed. The results showed that propafenone at two different $\mathrm{pH}$ conditions (at $\mathrm{pH} 4.0$ and at $\mathrm{pH} 9.0$ ) was extracted with equal amounts (Fig. 5).

In the analysis of the blood, the obtained dry residue was dissolved in $3 \mathrm{ml}$ of mobile phase and chromatographed for quantitative analysis. In the case of propafenone, 41.3-60.6 $\mu \mathrm{g} / \mathrm{L}$ substance was determined in the blood $(5 \mathrm{ml})$ samples and 0.46-0.88 $\mu \mathrm{g} / \mathrm{L}$ in the blood ( $3 \mathrm{ml})$ samples in a single dose 150 mg was administrated (Fig. 6). 
Propafenone in Blood Samples via HPLC

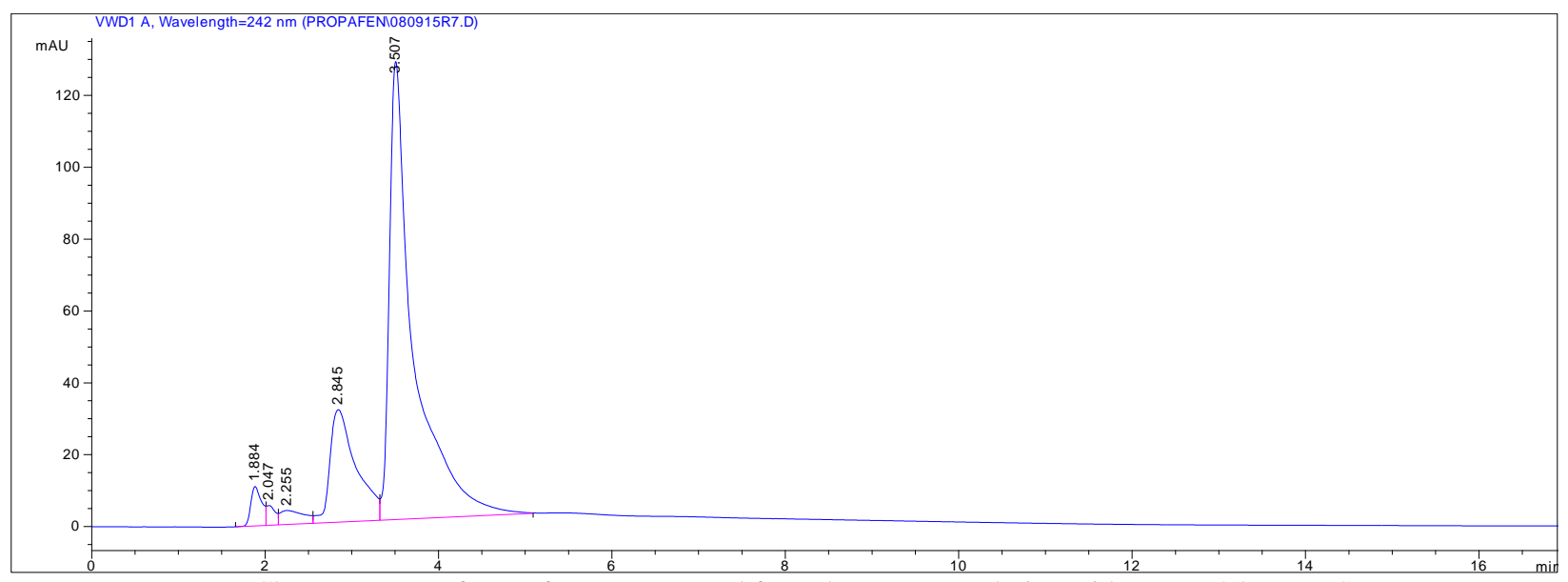

(a) Chromatogram of propafenone, extracted from the aqueous solution with a $\mathrm{pH} 9.0$ by HPLC

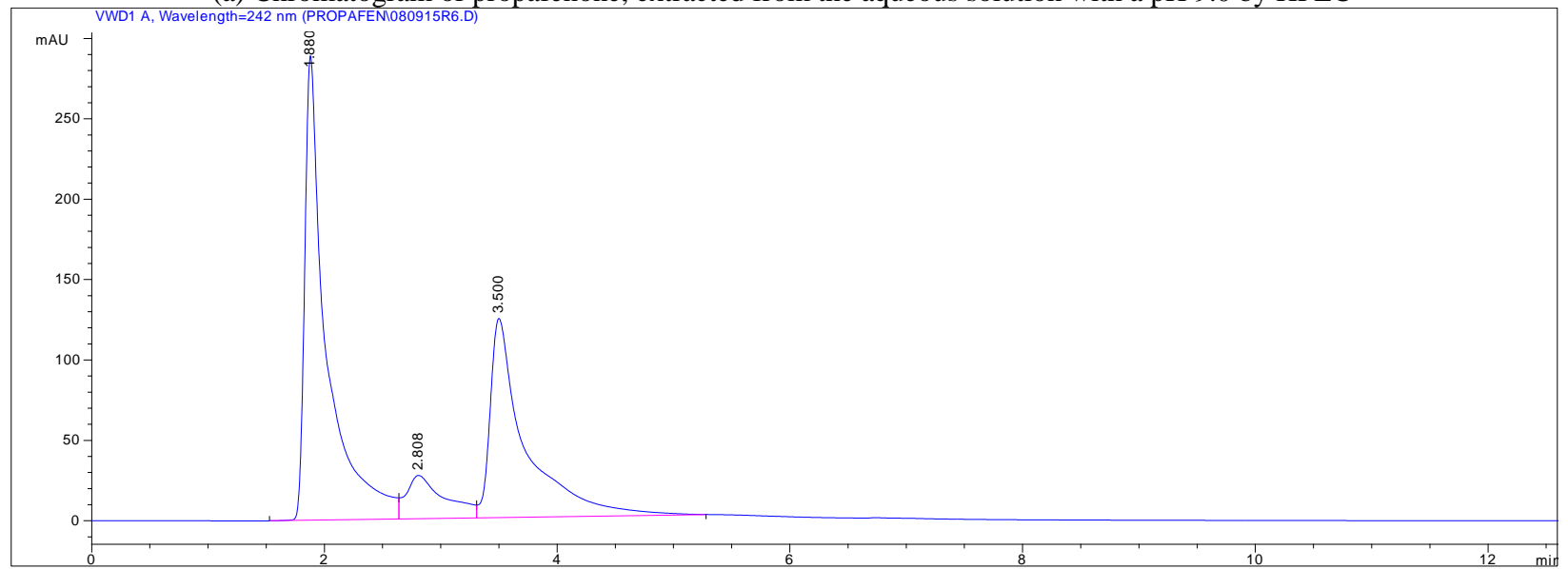

(b) Chromatogram of propafenone, extracted from the aqueous solution with a $\mathrm{pH} 4.0$ by HPLC

Fig. 5 Chromatograms of propafenone obtained from extracts.

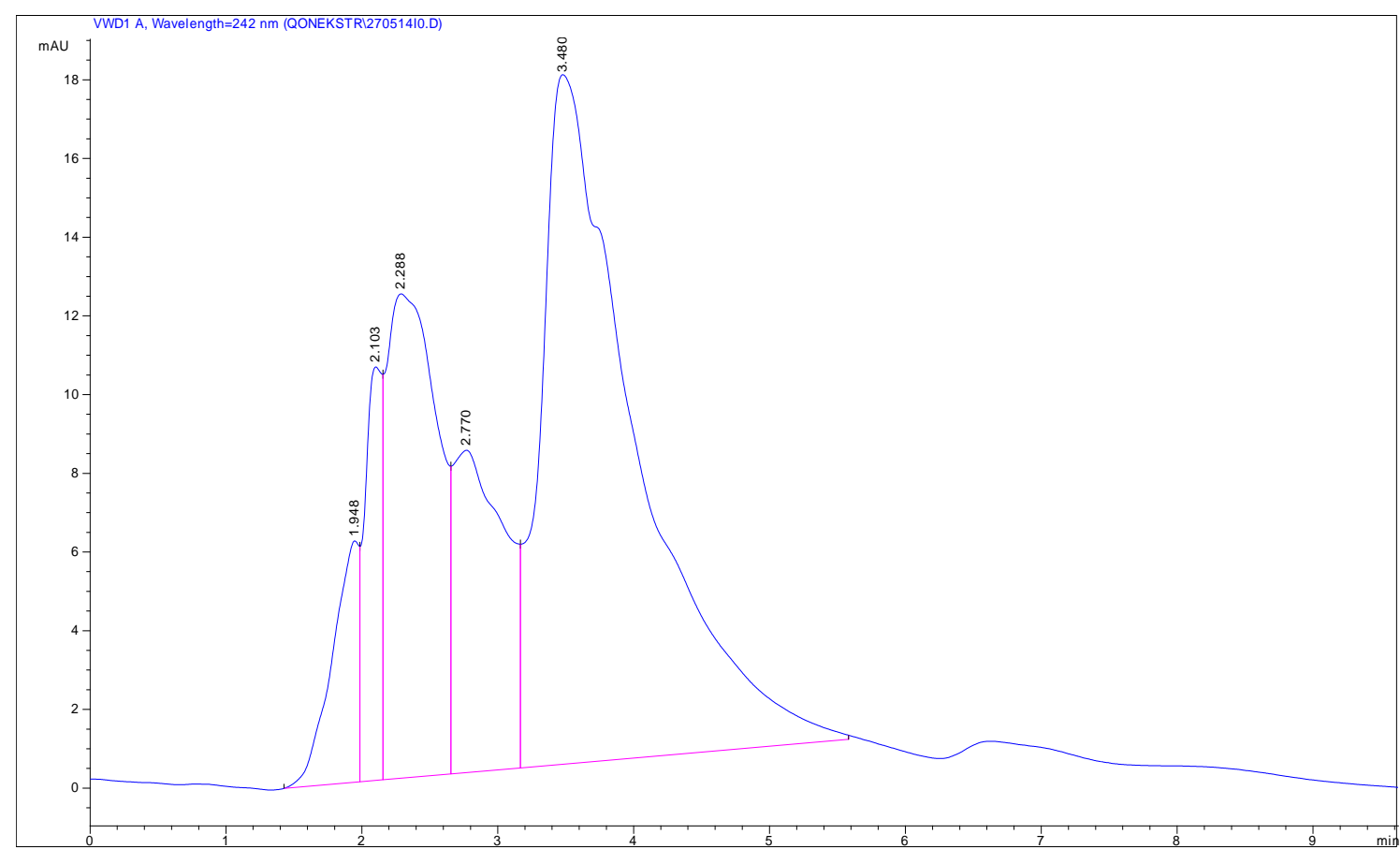

(a) chromatogram of the tested solution of propafenone which is isolated from $5 \mathrm{ml}$ blood (sample 1) via HPLC 


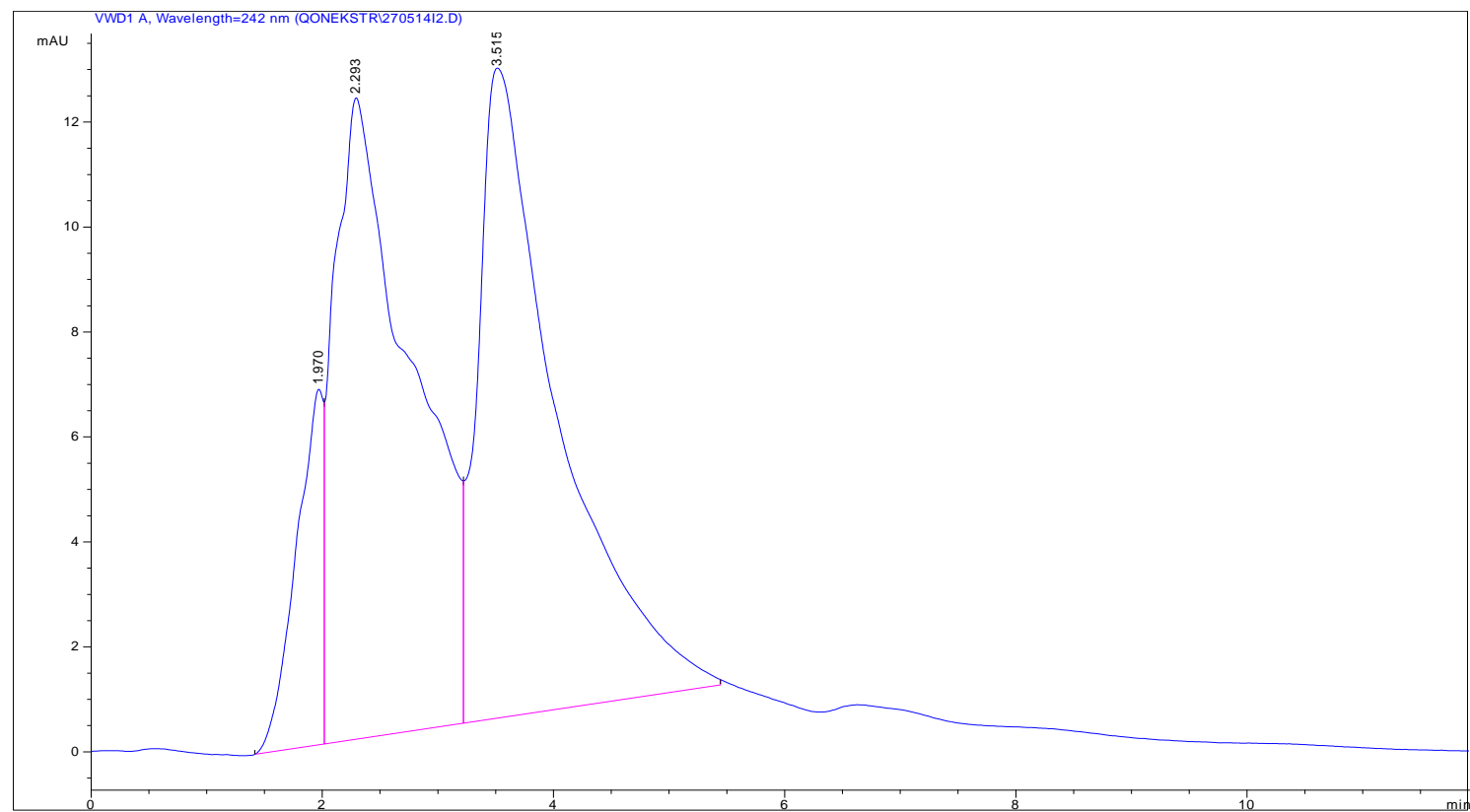

(b) Chromatogram of the tested solution of propafenone which is isolated from $5 \mathrm{ml}$ blood (sample 2) via HPLC

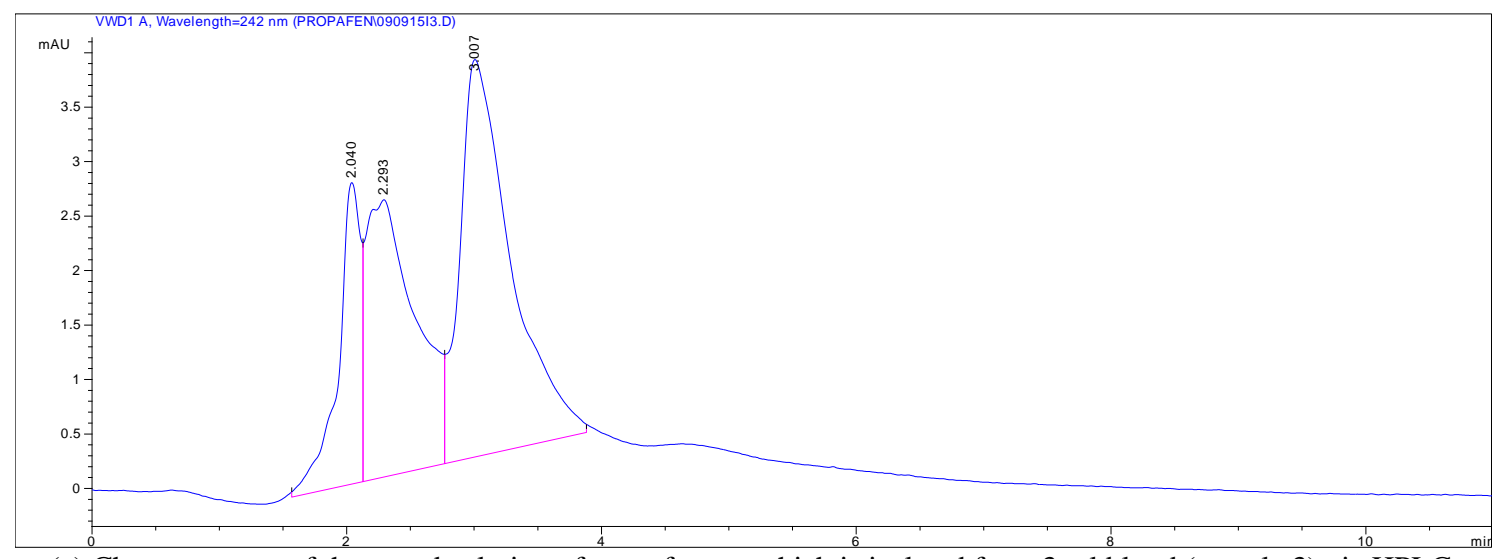

(c) Chromatogram of the tested solution of propafenone which is isolated from $3 \mathrm{ml}$ blood (sample 3) via HPLC

Fig. 6 Chromatograms of propafenone extracted from blood.

\section{Conclusion}

The proposed methods were found to be simple, accurate and precise for determination of propofenone in blood. Propofenone was detected at $\operatorname{Rf} 0.42 \pm 0.01$ by TLC method. TLC method can be used to determine the substance and to purify the extracts obtained from the blood for further UV spectrophotometric analysis. However, TLC method allows to determine and to purify the propafenone in the samples at higher concentrations. The UV spectrophotometric extract analysis illustrated that ethanol solution reaches two extremes (248 $\mathrm{nm}$ and $304 \mathrm{~nm}$ ). The amount of solution in extract was calculated based on response factor derived from a standard curve. The absorbance of the final solution was measured at $248 \mathrm{~nm}$. Hence, the liner range for propofenone in biological fluids detected by UV spectroscopy was $5-60 \mu \mathrm{g} / \mathrm{ml}$. The method for isolation, detection and quantitative determination of propafenone in the blood (in $3 \mathrm{ml}$ volume) was developed. The most suitable condition for extraction is using acetate buffer with $\mathrm{pH} 4.0$ and chloroform as an extracting agent. It is recommended to use the method of HPLC for quantitative analysis, which allows determining the drug at therapeutic concentrations. 


\section{References}

[1] Reiffel J. A., Ester N. A, M., Waldo A. L. Prystowsky E. N., and Dibianco, R. 1994. "A Consensus Report on Antiarrhuthmic Drug Use.” Clinical Cardiology 17 (3): 103-16.

[2] Golitsyn, S. P. 2000. "The Edge of the Benefits and Risks in the Treatment of Ventricular Arrhythmias of the Heart." International Journal of Medical Practice 10: 56-64. (in Russian)

[3] Zipes, D. P., Camm, A. J., Borggrefe, M., Buxton, A. E., Chaitman, B., Fromer, M., Gregoratos, G., Klein, G., Moss, A. J., Myerburg, R. J., Priori, S. G., Quinones, M. A., Roden, D. M., Silka, M. J., Tracy, C., Smith, S. C., Jr. Jacobs, A. K., Adams, C. D., Antman, E. M., Anderson, J. L., Hunt, S. A., Halperin, J. L., Nishimura, R., Ornato, J. P., Page, R. L., Riegel, B., Blanc, J. J., Budaj, A., Dean, V., Deckers, J. W., Despres, C., Dickstein, K., Lekakis, J., McGregor, K., Metra, M., Morais, J., Osterspey, A., Tamargo, J. L., and Zamorano, J. L. 2006. "ACC/AHA/ESC 2006 Guidelines for Management of Patients with Ventricular Arrhythmias and the Prevention of Sudden Cardiac Death: A Report of the American College of Cardiology/American Heart Association Task Force and the European Society of Cardiology Committee for Practice Guidelines." Writing Committee to Develop Guidelines for Management of Patients with Ventricular Arrhythmias and the Prevention of Sudden Cardiac Death Circulation 114: 385-484.

[4] Baman, T. S., Lange, D. C., Ilg, K. J., Gupta, S. K., Lui, T. Y., Alquire, C., Armstrong, W., Good, E., Chugh, A., Jongnaranqsin, K., Pelosi, F. Jr., Crawford, T., Ebinger, M., Oral, H., Morady, F., and Boqun, F. 2010. "Relationship between Burden of Premature Ventricular Complexes and Left Ventricular Function." Heart Rhythm 7 (7): 865-9.

[5] Franck, C., Jean, P. G., Marline, H., Emmanuelle, V. C. L., and Bernard, P. 2003. "Fatal Propafenone Overdoses: Case Reports and a Review of the Literature." Journal of Analytical Toxicology 27 (8): 595-9.

[6] Vozeh, S., Haefeli, W., Ha, H. R., Vlcek, J., and Follath, F., 1990. "Nonlinear Kinetics of Propafenone Metabolites in Healthy Man." European Journal of Clinical Pharmacology 38 (5): 509-13.

[7] Fonck, K., Haenebalcke, C., Hemeryck, A., Belpaire, F., Jordaens, L., Calle, P., and Buylaert, W. 1998. "ECG Changes and Plasma Concentrations of Propafenone and Its Metabolites in a Case of Severe Poisoning." Clinical Toxicology 36 (3): 247-51.

[8] Rambourg-Schepens, M. O., Grossenbacher, F., Buffet, M., and Lamiable, D. 1999. "Recurrent Convulsions and
Cardiac Conduction Disturbances after Propafenone Overdose." Veterinary and Human Toxicology 41 (3): 153-4.

[9] Mozayani, A., Carroll, Y., and Nix, R., 1999. "Propafenone Distribution in a Medical Examiner Case." Presented at the Annual Meeting of the Society of Forensic Toxicologists, Puerto Rico.

[10] Dhandapani, B., Keerthi, J., Naik, M. B., Lavanya, L., Priyamvadha, D. L., Manjeero, K. K, Anusha, N. H., and Baboo, R. V. C. 2010. "Spectrophotometric Estimation of Propafenone in Bulk Drug and Its Pharmaceutical Formulation." International Journal of Pharmaceutical and Biomedical Research 1 (1): 49-53.

[11] Shao, H., and Wang, J. 2001 "Determination of Propafenone Hydrochloride Tablets and Injection by HPLC." Chinese Journal of Pharmaceuticals. Accessed September 4, 2015. http://en.cnki.com.cn/Article_en/CJFDTOTAL-ZHOU20 0110014.htm

[12] Jadhav, M. L., and Tambe, S. R. 2013. "Implementation of QbD Approach to the Analytical Method Development and Validation for the Estimation of Propafenone Hydrochloride in Tablet Dosage Form." Chromatography Research International 2013 (6): 1-9.

[13] Tan, W., Li, Q., McKay, G. and Semole, H. A. 1998. "Identification and Determination of Phase I Metabolites of Propafenone in Rat Liver Perfusate." Journal of Pharmaceutical and Biomedical Analysis 16 (6): 991-1003.

[14] Wu, Y. J., Ma, M. M. and Zheng, S. 2004. "Enantioselective Essay of $\mathrm{S}(+)$ and $\mathrm{R}(-)$ - Propafenone in Human Urine by Using RP-HPLC with Pre-column Chiral Derivatization." Journal of Zhejiang University Science 5 (2): 226-9.

[15] Ashraf, M., and Rouini M. 2004 “A Rapid HPLC Assay for the Simultaneous Determination of Propafenone and Its Major Metabolites in Human Serum." Analytical Sciences. 29 (9): 1307-11.

[16] Sagar, S. P., Ravi, K., Sasmita, K. A., and Kalyani, S. 2014. "RP-UFLC Method for Estimation of Propafenone in Tablets." International Journal of Pharmaceutical Sciences and Nanotechnology 7 (4): 2671-6.

[17] Neha, S., Sanjay, W., and Rasika, T. 2013. "Quantitation of Propafenone HCI in Presence of Its Degradation Product by RP-HPLC: Application to Pharmaceutical Dosage Form." Journal of Pharma Reseach 2 (8): 6-11.

[18] Alikhodjaeva, M., Atahanov, A., Aslanova, Y., and Xamdamov, M. 2014. "Development of Methodology of Chromatographic Screening of Antiarrhythmic Drugs." Presented at the Ghent Symposium on Alternative Sampling Strategies in Toxicology and Therapeutic Drug Monitoring. Ghent, Belgium. 